Ruslana Lutsiv, Ph.D. student, Department of International Economic Relations West Ukrainian National University (Ternopil, Ukraine)

Oleh Chukhnii, Lecturer, Department of Social Studies, Humanities and Sciences University of Modern Knowledge (Kyiv, Ukraine)

\title{
DIGITAL ADAPTATION OF CITIES IN THE ERA OF MODERN CHALLENGES
}

Abstract. Urbanization today is one of the most important trends in planetary development. 2020 has marked the greatest period of uncertainty and economic volatility our generation has ever faced.

The COVID-19 outbreak has made a significant difference to our way of life. While scientists estimate that by 2050,68\% of the world's population will live in cities, there is a growing need to design pandemic-resistant cities. Smart cities are one of the essential needs for reducing this as well as other pandemics. This study reviews recent approaches and presents potential solutions that can be exploited by health-centric smart cities to relieve impacts of any pandemic.

Keywords: smart city, pandemic-resistant cities, IT, COVID-19 outbreak, monitoring and detecting outbreaks, smart cities initiatives

\section{Introduction}

Throughout history, nothing has killed more human beings than infectious diseases, namely viruses, bacteria and parasites that cause them. They even cannot be compared with natural disasters like earthquakes, volcanoes or wars. Firstly, COVID-19 shows both how vulnerable we are and how we can avoid similar pandemics in the future. Secondly, COVID19 is painfully demonstrating our interconnected global economy both helps spread new infectious diseases - and, with its long supply chains, is uniquely vulnerable to the disruption that they can cause. Finally, coronavirus is changing the world in unprecedented ways. This global crisis is affecting cities, technology, approaches to climate change, and the lives of vulnerable people.

Thus, the novel coronavirus which originated from Wuhan city, China, in December 2019 is expected to profoundly change the way health information will be managed in the $21^{\text {st }}$ century. As the disease has spread all over the world, the need for more effective management of critical information is evident [Rehman, et al. 2020, p. 230]. It is quite obvious that 
governments and civil society should coordinate their efforts to create levels of digital inclusion in cities [Allam, Jones 2020, p. 46]. In fact, if the countries wish to fight this pandemic and the ones which might emerge in future, smart cities can be used as one of the best resources [Trencher, Karvonen 2019, p. 610].

Many researchers all over the world have been trying to develop vaccine which will save millions of lives. As of beginning of December 2020, a COVID vaccine developed by Pfizer/BioNtech has been approved for use in the UK and the first doses have been given to patients. Trials of the Oxford University/AstraZeneca vaccine show it stops $70 \%$ of people developing COVID symptoms. Other trial results are also expected in the coming weeks. Data on the Russian Sputnik vaccine, which works like the Oxford one, suggests it is $92 \%$ efficient. Janssen's trial is recruiting 6,000 people across the UK, in a total of 30,000 volunteers worldwide, to see if two jabs give stronger and longer-lasting immunity than one. Wuhan Institute of Biological Products and Sinopharm in China, and Russia's Gamaleya Research Institute are all in final testing ${ }^{1}$.

However, in the beginning the risk of spreading COVID-19 has been reduced by using smart city technologies, like smart healthcare, smart logistics etc. [Kummitha 2020, Webb, Toh 2020, Mohammadi, et al. 2018]. Without the vaccine, the implementation of such measures as lockdown, social distancing, the supply of essential services, and home quarantine of the infected persons can reduce the COVID-19 risk. The constituent parts of smart city can ease the implementation of these ideas, as shown in Fig. 1 [Shah, et al. 2019, Moreno, et al. 2017, Peng, W., Gao, W., Liu, J. 2019].

\footnotetext{
${ }^{1}$ https://www.bbc.com/news/health-51665497 [Accessed: 3 November 2020]
} 


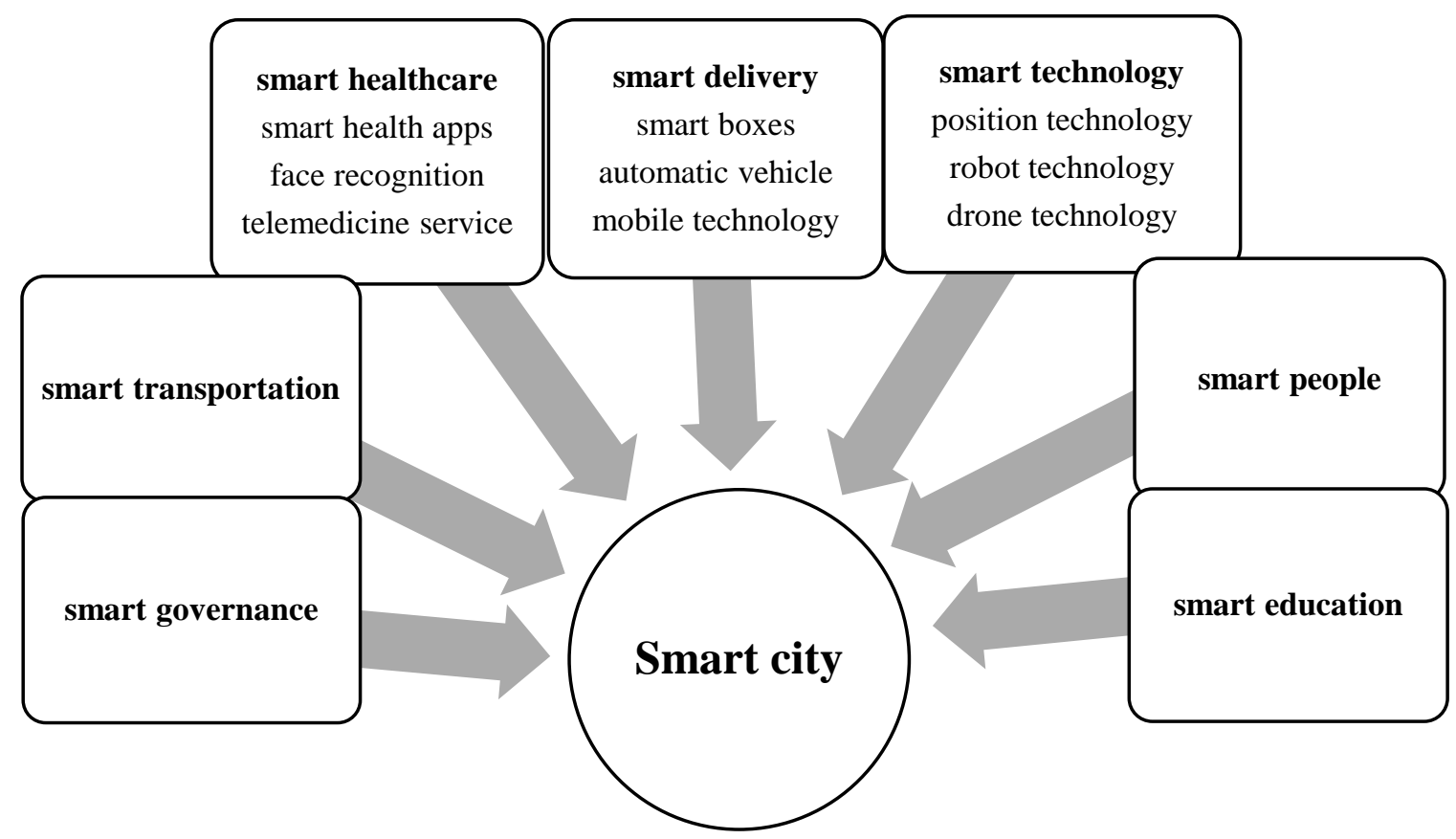

Figure 1. Smart cities component for reducing the COVID-19 cases

World populations are increasingly moving from rural to urban centers, making for larger cities with greater population density than ever before. This is a global phenomenon across the developed and emerging economies. We are increasingly becoming an urban world. Since this trend is not expected to change in this century, large cities will be the home to most part of the mankind. Despite its positive influence, urbanisation causes pollution, energy efficiency, mobility, and security [Silva, Khan, Han 2018, pp. 697-713] and what is more, new highly-contagious diseases may emerge in densely populated areas. Additionally, international flights can increase the risk of spreading of different diseases which we have witnessed with COVID-19. This highly contagious virus rapidly reached all continents in just a few weeks. Since any contagious diseases emerge anywhere and anytime, it is crucial for us to do whatever we can to better face a pandemic.

To fight this pandemic and the future ones we should be able to quickly process information in order to implement sound decisions. Thus, information management is of utmost importance for decision making processes. In such cases cities must be prepared to rapidly detect potential outbreaks of already known diseases as well as new ones.

Cities, as living organisms [Chamoso, et al. 2020, pp. 323-332], generate terabytes of data provided from different sources, such as lamp posts, public transportation, climatic stations, police vehicles, traffic lights, security cameras, hospitals, universities, museums, and any other 'element' that can be connected to a digital city's macrocosm [Costa, de Oliveira 
2020, pp. 228-243]. The ability to integrate different sources of data together with processing possibilities provided by data science and deep learning algorithms can be pivotal transformations in the $21^{\text {st }}$ century. Moreover, if cities and their citizens are considered as a symbiotic organism, a lot of data can be provided about an urban area. The integration of a city's cyberspace with social media and people's smartphones and gadgets can both lead to a more digital society and become a source for prevention and mitigation of virus outbreaks.

Since the beginning of the $21^{\text {st }}$ century there have been a couple of cases when diseases outbreak accelerated development in different spheres. Among them is SARS-CoV virus outbreak in 2003 which severely affected urban highly-populated areas in such cities as Beijing, Hong Kong, Taipei, Toronto, and Singapore [Ali, Keil, 2006, pp. 491-509]. However, SARS pandemic in 2002-2004 accelerated the growth of a small company Alibaba, which traded over the Internet. It is now the leader in retail in Asia. This growth was fueled by the anxiety and panic of people who tried to avoid contact with each other as much as possible almost the same as we see now. Then 2009 the H1N1 outbreak took advantage of the modern way of living and hit the world very hard and very quickly. It infected more than 1 billion people with their large globalised cities interconnected in a worldwide transportation network. Today it is the COVID-19 pandemic which hit the globe with a significant death toll, and the lessons from it should be thoroughly studied. Figs. 2 and 3 show how numbers of infected people have drastically changed since January 2020 which urges the world to think about precautious measures to prevent future pandemics. 

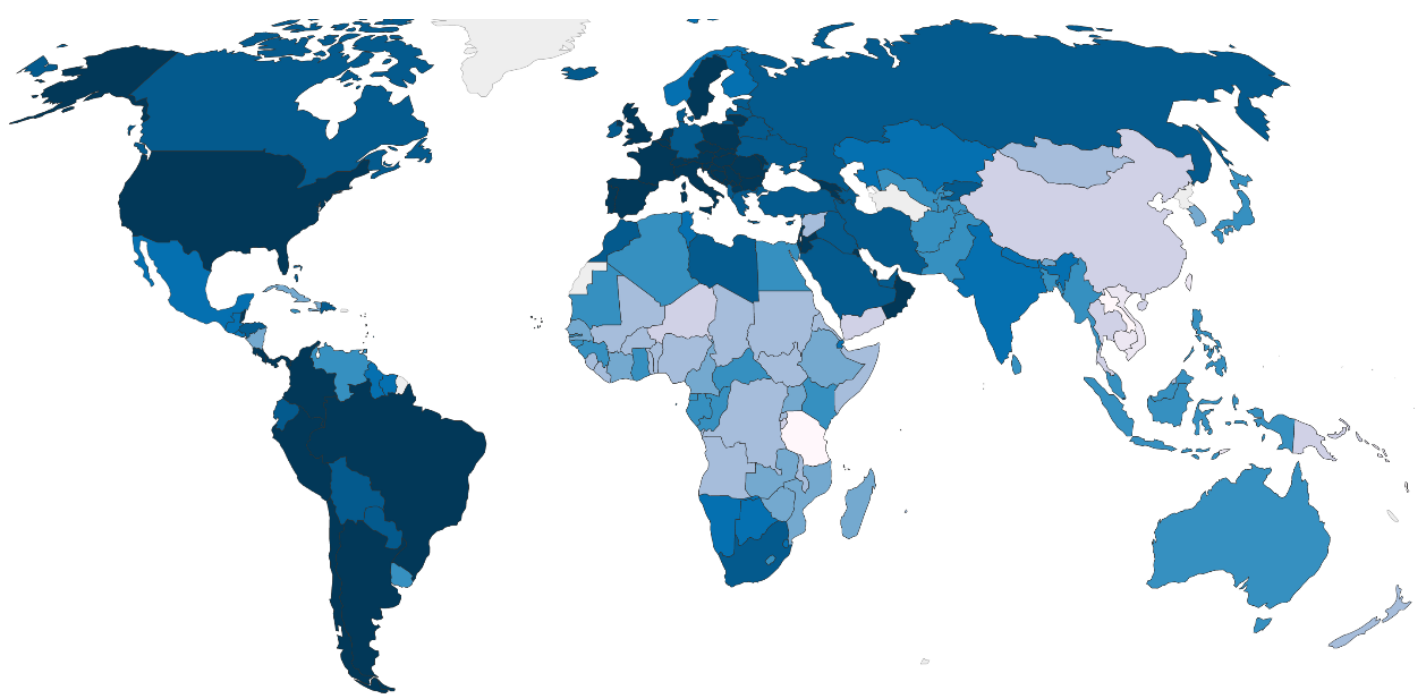

No data 0

10

50

100

500

$1,000 \quad 5,000$

10,000

$20,000>40,000$

Source: Johns Hopkins University CSSE COVID-19 Data - Last updated 10 December, 06:06 (London time)

Figure 2. Cumulative Confirmed COVID-19 cases in the world (map)

Source: https://ourworldindata.org/coronavirus-data-explorer

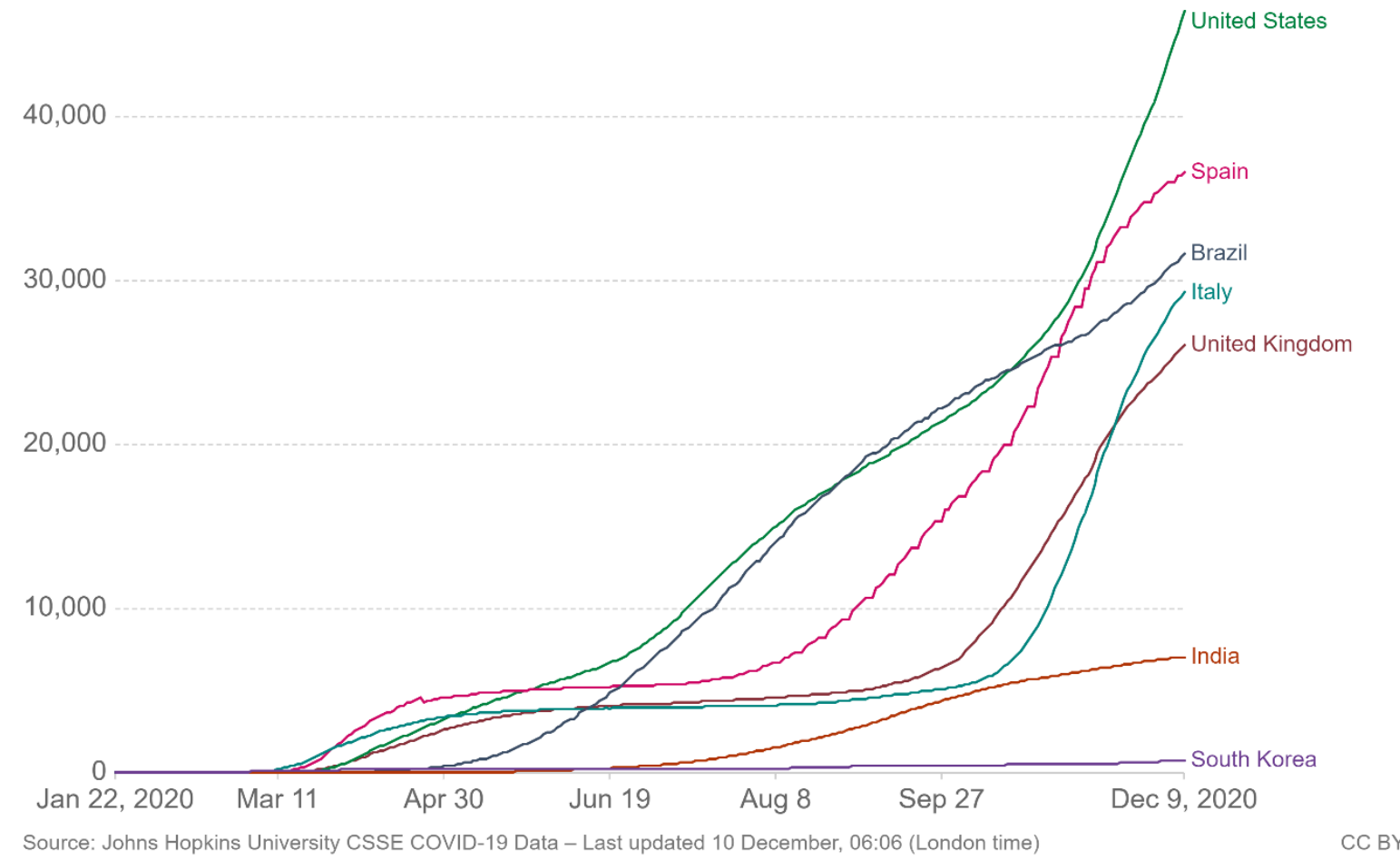

Figure 3. Cumulative Confirmed COVID-19 cases in the world (charts)

Source: https://ourworldindata.org/coronavirus-data-explorer 
Modern living in highly-populated cities with globalised businesses is most vulnerable for outbreaks of infectious diseases and the next pandemic is just a matter of time. Therefore, in this study we analyze recent developments that can better prepare cities to face this and the next pandemics, surveying technologies, and innovative approaches related to the evolution of the smart cities' paradigm. We surveyed the best practices and development trends in this area. Finally, the most innovative cities are described and potential directions to be followed are pointed out.

\section{Urban areas as emergencies prone environments}

The United Nations has called the COVID-19 pandemic "the greatest test that we have faced since the formation of the United Nations" ${ }^{2}$, making it clear that it is more than a health emergency, it is a systemic crisis that is already affecting economies and societies in unprecedented ways. COVID-19 and other pandemics are considered to be global but they usually start and spread from city to city. Current pandemic originated from the city of Wuhan, China, in December 2019. The city is large and highly populated. In addition, it is one of the main Chinese economic and transportation centres. Afterwards, this virus caused outbreaks in such big cities as Milan (Italy), Madrid (Spain), and New York (USA) which was difficult to control and it quickly disseminated to many European countries and the American continent as well. It is believed that the virus originated from human interaction with animals [Short, et al. 2015; Rabi 2020], but urbanization has helped to transport from cities outskirts to their centres and all over the world. In future we can always be under the threat of a new pandemic.

Urban areas are prone to any emergency such as fires, floods, chemicals leakages which require quick response. There have been developed some initiatives to cope with in critical situations [Astarita, et al. 2020; Soyata, et al. 2019]. Yet, is it possible to manage pandemics outbreaks as city emergencies?

Having studied the research in this field [Costa, et al. 2019, pp. 1-28], we have found out that it is possible to manage any emergency certain elements which are shown in Table 1:

\footnotetext{
${ }^{2}$ https://news.un.org/en/story/2020/03/1060702 [Accessed: 3 November 2020]
} 


\section{Table 1}

\begin{tabular}{|l|l|}
\hline Elements & Measures taken \\
\hline Detection & $\begin{array}{l}\text { any emergency can be detected by recognizing an irregular pattern that differs } \\
\text { from a normal behaviour in a city. It is either a higher temperature in some areas } \\
\text { which can indicate a fire emergency or an infectious disease outbreak if medical } \\
\text { assistance has been requested several times [Nikolay, et al. 2017; Xu, et al. } \\
2018] .\end{array}$ \\
\hline Alerting & $\begin{array}{l}\text { is done after an emergency is detected by sending warning messages through } \\
\text { emails, SMS messages, television broadcasts and even sirens or luminous signs. } \\
\text { The last two are deployed when detecting and warning about tsunamis [Bernard, } \\
\text { Titov 2015]. It is advisable to indicate critical places which should be avoided } \\
\text { for outbreaks prevention. }\end{array}$ \\
\hline Mitigation & $\begin{array}{l}\text { comes after emergencies have been detected and alerted [Samuel, Siebeneck } \\
\text { 2019]. This can be a daunting task in case of infectious diseases. To respond to } \\
\text { fire it is necessary to send out fire brigades, however, detecting diseases } \\
\text { outbreaks and screening infected people requires a range of measures such as } \\
\text { tracking, testing, preventive isolation, etc. }\end{array}$ \\
\hline
\end{tabular}

The COVID-19 pandemic which has been causing a lot of deaths has raised many questions how to detect, alert, and mitigate further potential outbreaks. Furthermore, as cities will be in the centers of the largest infective spread, present and future smart cities should be designed, implemented and managed in the way to be able to address disease outbreaks as highly critical emergency situations. This will make the data provided by cities the main ally of governments and health systems in the face of a pandemic.

Although alarming and mitigating measures are separate and independent procedures [Soyata, et al. 2019, Astarita, et al. 2020], we believe that the characteristics of known and future pandemics will require a more rigorous perception of crisis management, hence, warning and mitigation should be carried out simultaneously through a single process. 


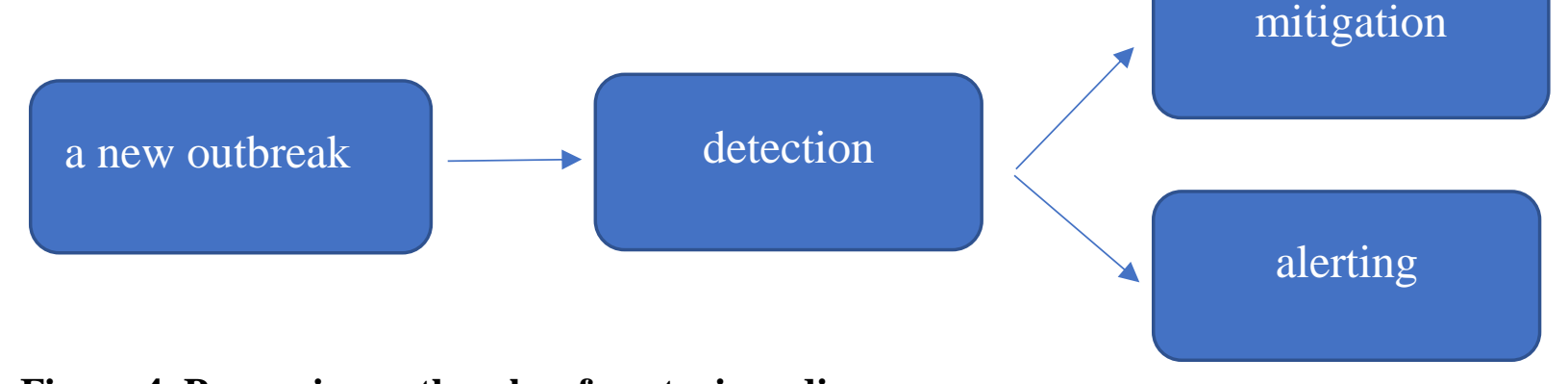

Figure 4. Processing outbreaks of contagious diseases

After all, we believe cities, especially smart ones, can cope with any disease outbreaks as they do with any emergency such as fires, floods, and earthquakes. Thus, the first stage is detection which is followed by immediate simultaneous mitigation and alerting procedures shown in Fig. 4. Alerting procedures are aimed at notifying affected people and the government, while mitigation is connected with tracking of people who have been infected. In a smart city these two procedures can both share their data with each other and inform the citizens. Yet these procedures are separated and independent ones in a smart city [Costa, et al. 2019, pp. 1-28].

In general, cities with deep inequalities and a big number of poor citizens are expected to be potentially more vulnerable to new outbreaks. It is not easy to detect, mitigate and alert any outbreaks in places without adequate infrastructure in the event of new pandemics. Hence, cities must be prepared to confront highly contagious diseases.

\section{Smart cities initiatives in fighting the COVID-19}

The sources about the COVID-19 outbreak show that the virus quickly spread over China because the country did not adopt proper measures at the initial stage [Pirouz, et al. 2020, pp. 1-21]. However, the same study proves the positive effects of quarantine which was introduced to fight the disease and its dissemination. Even though currently European countries are facing the second wave of the COVID-19 pandemic, many up-to-date studies and reports favour coordinated identification of new cases.

There are many new technologies which have been adopted by large cities to track, mitigate and alert infected people, but nobody insists that they are the only ones [Lu, H.P., Chen, C.S., Yu, H. 2019, p. 727]. Thus, digital bureaucracy is going massive as the coronavirus pandemic has caused officials to accelerate incredibly. China has broken all records by building a huge hospital in Wuhan with an area of almost 60 thousand square 
meters in just 10 days. South Korea conducted speed tests for 200 thousand citizens and used smartphones to track the movements of the infected people in order to promptly notify healthy people of such movements. All of these measures could be improved further if there were more smart cities in the world. According to a recent study by the University of Glasgow, out of 5,500 large cities, only 27 can boast of such a level of technological development [Joss, et.al 2019].

The authorities will undoubtedly adopt these tactics, and investments will shift towards smart cities. In the event of new crises, it will become important to carefully monitor and maintain order. This will mainly benefit smart governments, specialist companies like Cisco, Microsoft and Siemens, and digital urban startups across Europe and the US.

Nowadays, many cities install intelligent cameras which easily detect suspicious behaviour and different incidents. Artificial intelligence (AI) algorithms are used to identify criminals and even acts of terrorism. During the COVID-19 pandemic face recognition algorithms caused a lot of debate concerning privacy issues, but they greatly contributed to detecting and tracking potentially infected people in the crowds.

Moreover, new technologies and paradigms are supporting more comprehensive and efficient decisions in critical issues, affecting business, sports, science, and even how cities detect emergencies. The pandemic is also accelerating deeper, longer-term trends affecting cities, such as the digitalization of retail, the move to a cashless economy, the shift to remote work and virtual delivery of services, and the pedestrianization of streets. The pandemic could finally humanize the use of high technology in cities.

\subsection{Collective intelligence approaches in fighting COVID-19}

Smart city models of the previous generations were all about regulation and control which looked like an online state. What is emerging in this pandemic is good programs and protocols that build community. Beyond the national and institutional response, there are (at least) five ways to help city governments, companies and city communities fight COVID-19 through collective intelligence approaches.

\section{Open exchange of information with citizens on the spread and management of}

COVID-19. Based on open data provided by government agencies, private sector companies are using the city as a platform to develop their own real-time dashboards and mobile applications to further raise public awareness and effectively disseminate disease information. This was the case with Corona NOW, Corona Map, Corona 100m in Seoul, Korea, which allow people to visualize data on confirmed coronavirus patients, as well as the nationality of 
the patients, gender, age, which places the patient has visited, and how close citizens are to those patients with coronavirus. Developer Lee Jun-young, who created the Corona Map app, said he built it because he found the official government data was too difficult to understand ${ }^{3}$.

At the same time, in city state Singapore, the dashboard developed by UpCode cleans up the data provided by the Ministry of Health Singapore's own dashboard (which is exceptionally transparent with regards to coronavirus case data) to make it cleaner, easier to navigate, and significantly more insightful. For example, it informs about the average recovery time for those who are infected, UpCode makes its platform available to others to reuse in other contexts ${ }^{4}$.

2. Mobilizing community response to tackle COVID-19. Crowdfunding is being used in a variety of ways to generate short-term targeted funding for a variety of meritorious reasons opened up by the COVID-19 crisis. Examples include helping to raise funds for community events for those directly affected by the crisis, supporting tools and products that can help cope with the crisis (such as purchasing PPE), and pre-purchasing products and services from local shops and craft makers. A large proportion of the UK mutual aid initiatives of more than 1,000 people are now moving towards crowdfunding as a way to quickly respond to new and emerging needs at the citywide and hyper-local (i.e. street and neighborhood) levels.

The Aberdeen City Mutual Aid group has created a crowdfunding community fund to cover the costs of building a network of volunteers throughout the city, as well as any costs associated with grocery shopping, fuel costs for delivery, and other essential supplies. Likewise, the Feed the Heroes campaign was launched with an initial goal of raising €250 to pay for food supplies for frontline employees who spend extra hours at Mater Hospital, Dublin during the coronavirus outbreak.

The need to quickly secure additional funding for local communities and organizations addressing the various issues and concerns posed by COVID-19 has led many local governments in the UK, such as Lambeth Council, Portsmouth City Council and Coventry City Council, to match donations from crowds for projects with government grants. In other countries, crowdfunding initiatives have been set up to help keep local businesses afloat by purchasing products from them. In cities like New York, similar initiatives were created to help small, independent restaurants raise funds to provide emergency relief to employees who have been laid off.

\footnotetext{
${ }^{3}$ https://www.smartcitiesworld.net/news/news/south-koreato-stepup-online-coronavirus-tracking-5109

${ }^{4}$ https://www.smartnation.gov.sg
} 
3. Development of joint economy to meet new socio-economic needs. Along with the rapid growth of demand for services from food and food delivery services such as Deliveroo, Peapod, Instacart, FreshDirect or BuyMie (vital providers for those in social distancing), community and non-profit collaborative economy initiatives are also emerging. Deliveroo said 3,000 new restaurants have added their business to the platform) while Randall.ie is a dedicated website that was built to connect people who are in self-isolation with an army of volunteers.

GoodGym has partnered with registered charities and state or local government agencies in various UK city centers and boroughs covering Barnet to York as a way to get their DBS-Verified volunteer community to provide delivery and basic tasks for vulnerable people and those who have been discharged from the hospital. Saving Hours, a London-based timekeeping platform, is currently asking its community to complete a brief to see how it can best help its community in light of the pandemic.

In the Canadian city of Guelph ${ }^{5}$, civil innovators and others have combined resources and people-centered initiatives into one online place to make it easier for residents to find or offer different types of assistance. In Paris and across France, a collaborative economy collective of food and agricultural industry actors has formed what it calls a "solidarity collective" to help provide fresh, local food and nutrition for hospital staff and caregivers. The team consists of MiiMOSA, a food and agriculture crowdfunding platform, food delivery companies Geev, Rutabaga, private and tiered courier and others. So far, the team has crowdfunded enough funds to cover the costs of over 6,500 meals. In the meantime, the City of Philadelphia has compiled a list of places where students can get free meals during school closings.

4. Urban ecosystems makerspace is being used for the rapid development of medical equipment. The World Health Organization has warned that all countries should “optimize the availability of ventilation equipment". Along with governments attracting help from major manufacturers such as Dyson, Fiat, and General Motors, urban collaborative makerspaces are exploring alternative, distributed community-based development methods for this much needed equipment.

Starting with the Cavalcanti GUI in San Francisco, the Facebook Group, Open Source Covid19 Medical Supplies was established to evaluate, design, validate, and source manufacture of open source emergency medical supplies around the world, taking into

\footnotetext{
${ }^{5}$ https://guelph.ca/2020/12/city-of-guelph-responding-to-coronavirus/
} 
account different local delivery terms. In response to this challenge, the Open Source Fan was launched by the Dublin Open Source Project to address the acute shortage of fans locally, nationally and internationally. It offered contributions from over 600 engineers, designers, and healthcare professionals to create and validate ideas for open source fan designs that can be produced at scale. Less than a week after the project was launched, six prototypes were developed for easy-to-assemble mechanically controlled ventilators, which are ready for production and testing with validation from the Irish Chief Health Officer.

Meanwhile, in Milan, a team of Isinnova (Institute for Systems Integration Research) team, Massimo Temporelli and Fablab Milano created DIY respirators by modifying scuba diving equipment that can be bought at any Decathlon store, combining this with $3 \mathrm{D}$ printed components. The DIY system ensured access to life-saving respirators for nearly 500 patients in hospitals in Northern Italy.

5. Finding new ways to make social isolation less isolating. Along with Torino Social Impact, Nesta Italia and others have created an open source crowdsourcing platform Torino Come Stai? (Turin, How Are You?) While still in early stages of development, the platform aims to create a useful resource for those in quarantine. Website visitors complete a short survey asking them about their quarantine activities, if they have any unmet needs, if any of their neighbors have COVID-19 symptoms and are ready to be blocked. The anonymized responses will be used to visualize the overall view of Turin citizens about the outbreak and possibly to identify possible pain points where targeted action will need to be taken. Social media also plays a role in helping those in social distancing.

\subsection{Improving cooperation between cities}

Different technologies are exploited by airports as well to face challenges posed by Covid-19. Some world airports with the help of technology companies have already begun to prepare to receive passengers, adhering to the new requirements. The airports in Helsinki, Frankfurt am Main and Copenhagen provide testing facilities for their passengers.

Yet, at the beginning of the pandemic, the American Veovo has proposed several solutions that will maintain social distance and track the density of the crowd ${ }^{6}$ :

- "Virtual queueing" will allow passengers to book check-in time in advance so as not to stand in line. The available time intervals are adjusted in real time, taking into

\footnotetext{
${ }^{6} \mathrm{https} / / /$ veovo.com/discover/news/airport-social-distancing-solution/
} 
account various factors, such as the speed of the queue and so on. This allows passengers to arrive at the most optimal time.

- "Passenger density management" with the help of IoT sensors allows tracking crowds density in terminals, based on which airport staff can make appropriate decisions.

The solution bundles location analysis from various IoT sensors, with machine learning and an alert framework, to give a detailed view of how people move and dwell. From typical crowding zones like check-in and security to areas like gates and concessions, it continuously monitors and analyses movement to highlight the degree of risk in real-time.

Live heatmaps and dashboards show operators a reliable breakdown of the current situation, triggering tailored alarms and automated actions if density thresholds, based on current guidelines are exceeded. Recommendations to limit crowding can include capping entry to busy escalators or stairwells, adjusting security lane openings, changing call-to-gate times, updating digital signage, or distributing gate and luggage belt allocations. With these valuable people movement insights, operators can also improve the responsiveness of sanitation service providers, directing teams to where cleaning is most needed.

Besides real-time insights, the Veovo platform also includes predictive capabilities that not only help operators manage crowding in real-time but also plan for days, weeks and months ahead. It offers detailed insights into people's movement habits, and how factors like time of day or day of the week, or other events, affect passenger behaviour.

However, the experience of many cities shows that analyzing data from different channels shows patterns, solves problems faster, more efficiently, plans, saves money, and ultimately makes residents' lives more comfortable.

Collaborative approaches also help improve cooperation between cities. Smart cities networks bring together knowledge and resources about effective responses to the pandemic in real time. There are a lot of such examples worldwide ranging from more centralized to completely open ones. Bloomberg charities are actually convening public health experts and city leaders to help cities respond to the coronavirus. The organization also teamed up with the National League of Cities to develop a local action tracker that centrally collects and shares actions taken by local leaders in response to the COVID-19 pandemic.

Other more open and collaborative models have emerged, such as Cities for the Global Health Platform ${ }^{7}$. It seeks to blur the traditional boundaries between local, regional, urban

\footnotetext{
${ }^{7}$ https://www.citiesforglobalhealth.org/
} 
levels of government in order to find collective answers to this crisis. The platform invites local and regional governments of all sizes from around the world to share their initiatives (e.g. plans, strategies, policies) that are a) designed specifically in response to the COVID-19 outbreak, or b) designed to address other health emergencies. such as health crises or epidemics. To date, over 270 initiatives have been implemented under this initiative.

Effective responses to a pandemic cannot rely solely on high-tech platforms or applications. In fact, the speed and immediacy with which some technologies - especially mass surveillance ones - are deployed in such countries as China, Thailand, Hong Kong, and the United Kingdom leave civil liberty and human rights defenders asking if they are scrutinized enough. Some experts noted that while technology may be useful to support specific purposes, such as contact tracing, mass surveillance is not necessary to contain the virus. The COVID-19 pandemic has stimulated the development and implementation of data and its sharing, so a similar strategy needs to be pursued. To do this, smart city professionals and others must explore more hybrid collective intelligent responses that combine centralized and decentralized modes of coordination, and that work to standardize protocols for enhanced smart city connectivity.

Despite such shortcomings, digital infrastructure and approaches to collective intelligence are proving to be important tools in how cities manage COVID-19. They also provide a broader set of valuable lessons on how cities can better work with citizens, private companies and other public authorities using technology to solve social problems.

\subsubsection{Urban pandemic management}

As the world urbanizes, sustainable development, economic growth and citizens' welfare depend increasingly on the successful management of urban growth which is pivotal during the COVID-19 pandemic. Cities, with the right technology and the know-how to govern it, can lead the way in solving problems in energy, transportation, healthcare, education and natural disaster response, while making their communities more inclusive, resilient and sustainable.

Before considering the possibilities for collective intelligence, it is important to recognize that effective management of pandemics in cities depends on a number of important mechanisms, many of which will not include collective intelligence approaches:

- although city and subnational governments are often the first to respond to public health emergencies, they depend on good coordination and collaboration with central government and other stakeholders. Taiwan, for example, is known for its 
comprehensive and collaborative approach to pandemic preparedness and response. Its central government works with lower levels of government, as is the case in Taipei, Tainan and Kaohsiung, as well as government hospitals;

- good governance to ensure public health and safety and the dissemination of clear, accurate and reliable information widely. For example, the Conference of Mayors of the United States of America has produced an online resource with best practices and guidelines to assist city leaders and staff;

- a multisectoral approach that includes many levels of government and people with different specialties, including policy development, legislative review and drafting, animal health, public health, patient care, laboratory diagnostics, laboratory test development, communication expertise, and disaster management disasters;

- engaging communities to leverage local knowledge, expertise, resources and networks and ensure public acceptance and adherence to political decisions such as social distancing;

- ensuring the availability of "hardware" and "software" to prevent a pandemic. "Hardware" refers to effective surveillance systems, medical support and health infrastructure, while "software" refers to established and tested protocols, proper education for health care providers, and close collaboration and planning that occurs between qualified doctors, nurses and other actors from regional to local levels. The varied and ad-hoc approach taken by different cities shows that in many cities both software and hardware are outdated.

Finally, we acknowledge that any study on COVID-19 and its impact may be out of date before it is published, just as some of the examples we have listed above may change significantly as communities and cities adapt to the outbreak.

\subsection{Current and Potential Initiatives of Smart Cities}

The emergence of epidemic diseases is expected to significantly transform the way we live and interact with the world. It is worth mentioning so called "black swans" that changed the course of history in the past. Events like the "black swan" (economic recession and pandemics as well) change the direction of politics, economics and business, and affect the course of history. The Black Pestilence in the 1300s destroyed the feudal system in Europe, replacing it with more modern employment relationships. Just three centuries later, the deep 
economic crisis caused by the Hundred Years' War between England and France led to a new spurt of innovation that radically modernized agriculture.

The 2008 financial crisis also contributed to new technologies. In Western countries, companies like Airbnb and Uber instantly became popular, because in the crisis, people tried to save on everything: organize cohabitation and group up for travel. The trend was picked up by the video game industry and also changed course dramatically. In 2011, free in-app purchases were booming, thanks to Nexon in Asia and King in the West.

With the arrival of Covid-19, we are already seeing the first signs of how consumer and business behavior is changing. Airline profits are plummeting from travel abandonment, retail stores are running out of drugs, cereals and toilet paper, and working from home is becoming the norm. Some of these changes are direct but short-lived responses to the crisis. All of this will return to normal after the victory over the coronavirus.

However, some changes will remain, creating the foundation for long-term innovation and will dictate the business environment for years to come. For example, China used $5 \mathrm{G}$ patrol robots to monitor wearing of masks and body temperature in public places to help fight the coronavirus. So far, they can be seen in the airports and shopping malls in Guangzhou, Shanghai, Xi' an and Guiyang. The robots were equipped with five high-resolution cameras and infrared thermometers capable of simultaneously scanning the temperature of 10 people within a radius of 5 meters. If the robot detects a high temperature or no mask, it sends a signal to the appropriate institutions in real time.

Interestingly, these works are not a new invention specifically for the coronavirus situation. China has long used patrol robots, which have now been upgraded with new capabilities. The works integrate IoT, AI, cloud computing and big data technologies for environmental sounding, rapid decision-making and autonomous traffic control technologies, as well as behavioral sounding and interaction technologies ${ }^{8}$.

\subsubsection{Wuhan}

Widely known as the source of the COVID-19 pandemic, Wuhan is a 'Tier II' city in China (cities having from 3 to 15 million residents). Wuhan's Smart City planning started back in 2010, in a conference held by its Science and Technology Bureau, finishing their construction blueprint in July 2011. According to the authors ${ }^{8}$, this is the most 'perfect' system in China, paying high attention to smart health. The Wuhan's Smart Health approach

\footnotetext{
${ }^{8}$ https://www.smartcitiesworld.net/news/how-5g-poweredrobots-are-helping-china-fight-coronavirus-5154
} 
is intended to connect various healthcare systems and databases to enhance communication among patients, doctors, and other healthcare professionals. Automated systems are capable of exchanging patients' health records to ensure that correct information reaches proper healthcare professionals, reducing mistakes (e.g. nurses getting wrong data).

Besides Wuhan's Smart Health, the Chinese government has been using technologies to tell who must get into quarantine. In a partnership with Alipay, they are providing a colour QR code to citizens that install Alipay app on their smartphone. The QR code may have three colours: green, meaning the user can move around; yellow, meaning the user must have a 7-day quarantine; and red, meaning the user must have a 14-day quarantine ${ }^{9}$. The app gets users' information provided by the healthcare system and it also tracks their pharmacy purchases and movements to verify if they have had contact with infected people. Although this approach can help determine who must self-isolate, some people are reporting that the app sends personal data, as user localisation to police enforcement, which may raise some privacy concerns.

\subsubsection{Singapore}

The city-state of Singapore, one of the world's largest financial and transport hubs, has showed excellent results in the fight against the coronavirus pandemic. The key to success is modern technology and a quick response to threats [Baharudin H. 2020].

The population of Singapore has reached 6 million people, and thanks to the world's best airport, Changi, tens of millions of people visit the city-state every year. Close ties with China, the country's main business partner, led to the fact that the first cases of coronavirus in Singapore were recorded just a few weeks after the outbreak of the epidemic in China. The Singaporean authorities very quickly reacted to the first cases of the new "Wuhan flu" and, based on the experience of fighting SARS in 2002-2003, developed and applied a whole set of measures to combat the threat.

First, relying on modern smart city technologies, Singapore began to track all cases of infection and identify chains of connections between people, which made it possible to quickly isolate all possible carriers of infection. Since 2018 Singapore has been the leader in the ranking of the world's smart cities due to its developed infrastructure and the successful implementation of modern IT technologies. Moreover, Singapore has created and is using a

\footnotetext{
${ }^{9}$ https://www.paymentssource.com/news/alipays-coronavirus-health-codefeedspayment-data-to-police
} 
"digital twin of the city", which allows for a quick and effective analysis of various situations and options for responding to force majeure.

Secondly, in Singapore, a comprehensive system of diagnostic tests was quickly developed and deployed, which effectively checks every person arriving in the country within three hours of quarantine. This speed of reaction to the threat made it possible to quickly localize and isolate all potential carriers of the Covid-19 infection, and a single state database quickly identified possible human contacts.

Thirdly, from the beginning of February, everyone who enters a government or commercial building is required to go through the identification procedure and leave their contact details. As a result, literally a few hours after the arrival of new people in the city, the authorities see in real time all possible connections of a person and make a decision to isolate him or lift restrictive measures.

The key to success is modern technology and a quick response to threats. It is obvious that before using all the "smart technologies", the Singapore authorities have invested billions of dollars in the development of modern technologies and the creation of Virtual Singapore the digital twin of the city for a decade. An important role in the success of the fight against the infection was played by the discipline of Singaporeans, who have long been accustomed to "without objection" follow the orders of the authorities. An efficient economic system, an almost complete absence of corruption and the competent use of modern technologies have allowed Singapore to avoid a serious outbreak of infection in the country.

Currently the Singapore government is setting up a new office to speed up digitization and is beginning a gradual economic recovery after Covid-19. Communications and Information Minister C. Iswaran said that Covid-19 had irreversibly changed everyone's lifestyle, adding, "While many of us may have made the necessary adjustments to work, study or communication from home because we own digital technology, this does not apply to some people, elderly and vulnerable among us"10.

Digital ambassadors, who will be full-time employees and volunteers, will help the elderly, as well as shop owners in hawker malls, public markets, coffee shops and industrial canteens, to switch to digital. The goal is to interact with 18,000 outlet owners by June 2021 and help them adapt to electronic payments, as well as teach digital skills to 100,000 seniors by March 2021. Also, for five months, a number of Singaporean businesses will provide a

\footnotetext{
${ }^{10} \mathrm{https} / / / \mathrm{www}$. straitstimes.com/singapore/iswaran-public-engagement-needs-to-be-two-way
} 
$\$ 300$ bonus per month to encourage more point-of-sale owners to use electronic payments and reduce cash flow.

\subsubsection{Seoul}

One of the clearest examples of how technology and data are being used to empower citizens takes place in Seoul. Here, the city used its citizens as mayor's philosophy for smart cities; an approach that aims to equip citizens with the same real-time access to information as the mayor. Seoul has gone further than most cities in making the city's COVID-19 outbreak information available to citizens. Its dashboard is updated several times a day and allows citizens to access the latest anonymized information about the age, gender, and dates of confirmed patients, the places they visited and when, after symptoms developed. Citizens can access even more detailed information; down to the visited restaurants and cinema rooms.

The aim is to provide citizens with the information they need to take precautions, selfmonitoring and accountability if they begin to show symptoms after visiting one of the infection points. To help allay people's fears and reduce stigma associated with businesses that have been identified as "hot spots", the city government is also providing citizens with information on nearby testing clinics and making "clean areas" (places that have been disinfected after visiting confirmed patients) available to search for users ${ }^{11}$.

\subsubsection{Jerusalem and Adelaide}

Itamar Kornfeld, head of Jerusalem's IT department stated that thanks to many investments the city has made in digital transformations over the last decade, the pandemic has not caught them by surprise, so they did not have to perform complex operations to meet all needs. Jerusalem's municipality created a virtual center for the treatment of city residents and allowed employees to stay at home. They also continued providing services via mobile phone. Jerusalem's IT department displayed all data from the Ministry of Health and other sources on its GIS platform in real time. In addition, within 48 hours, they developed an application that allowed citizens to see the current state according to the area or other parameters also in real time. They carried out these actions with the help of the Strategic Department of Jerusalem. Another ancillary technology was the CRM system, through which the social security department managed the accommodation of residents who needed to be isolated and transferred to the hotel, as well as who closely monitored the treatment of the

\footnotetext{
${ }^{11} \mathrm{https}: / /$ www.smartcitiesworld.net/news/news/south-koreato-stepup-online-coronavirus-racking-5109
} 
elderly. They have also set up a staffing center for municipal employees to keep in touch with those who continue to work, with those who have been sent on leave.

Additionally, Jerusalem's IT department conducted training with the Command of the Internal Forces, in which they practiced a long series of emergency scenarios in all areas. The training was attended by the mayor and all decision-makers at the state level. The training was conducted on a mobile simulation system developed by Elbit.

The coronavirus has led to significant changes in the work processes of the municipality of Jerusalem and the services it provides. People realized that a wide range of services can be obtained online without contacting municipal institutions which is a huge change $\mathrm{e}^{12}$.

The Australian city of Adelaide has launched a new online platform to share ideas to hear community views what the city should look like after recovering from Covid-19. To celebrate the recovery period and congratulate people on their return to the city, a huge heart was cut out on the lawn of Victoria's main square. "We liked the idea of sending "big green hugs' to our community, because more and more people are coming back to the city", said Sandy Vershoor, Lord Mayor of the Australian city ${ }^{13}$. The council said the break caused by the coronavirus would give everyone an idea of what the city might look like in the future and help them recover quickly from the social and economic consequences of the pandemic.

On the whole, we can say that Asia is leading the fight against COVID-19 by deploying smartphone applications specifically for that purpose, whereas many cities on other continents depend on their current digital health initiatives to defeat the disease. A lot has been done, but is much more is still ahead.

Having thoroughly studied key smart city initiatives all over the world, we believe they can be adopted by those ones which are currently experiences the second wave of the pandemic (Table 2). Yet, with advanced transformations should be used in case of further pandemics.

\footnotetext{
${ }^{12}$ https://www.jerusalem.muni.il/en/newsandarticles/municipality-news/corona-virus-updates/

${ }^{13} \mathrm{https} / / / \mathrm{www}$. smartcitiesworld.net/news/news/adelaide-invites-citizens-to-reimagine-the-city-after-thepandemic-5321
} 
Table 2

Smart city initiatives to face the pandemic

\begin{tabular}{|c|c|c|c|}
\hline City & Continent & Population & Initiatives \\
\hline Adelaide & Australia & $1.5 \mathrm{mln}$. & Recover + Reimagine online portal ${ }^{14}$ \\
\hline Helsinki & Europe & $0.6 \mathrm{mln}$. & Helsinki smart region $^{15}$ \\
\hline Jerusalem & Asia & $0.8 \mathrm{mln}$. & GIS platform; CRM system \\
\hline London & Europe & $8.9 \mathrm{mln}$. & $\begin{array}{c}\text { DigitalHealth. London programme (digital health } \\
\text { services) }\end{array}$ \\
\hline New York & $\begin{array}{c}\mathrm{N} . \\
\text { America }\end{array}$ & $8.6 \mathrm{mln}$. & NYeC; SHIN-NY ${ }^{16}$ \\
\hline Seoul & Asia & $9.7 \mathrm{mln}$. & $\begin{array}{l}\text { big data, AI, blockchain; selfquarantine app; } \\
\text { corona } 100 \text { m app; Coronamap }\end{array}$ \\
\hline Shanghai & Asia & $24.2 \mathrm{mln}$. & 5G-powered robots ${ }^{17}$ \\
\hline Singapore & Asia & $5.6 \mathrm{mln}$. & $\begin{array}{c}\text { LifeSG app; a mobile app TraceTogether; } \\
\text { WhatsApp channel }{ }^{18}\end{array}$ \\
\hline Wuhan & Asia & $11 \mathrm{mln}$. & $\begin{array}{l}\text { records exchange; Alipay QR code for quarantine; } \\
\text { smartphone tracking }\end{array}$ \\
\hline
\end{tabular}

The humanity has faced new challenges which require fast responses to mitigate the dramatic effects of this pandemic. COVID-19 forces people to reconsider their habits and look for unusual ways to interact. One of the biggest challenges is to learn to keep your distance where large groups of people used to gather. In this case technological solutions can come in handy. Each city has been trying to apply the best technological solutions which are suitable and available in their cases as there is no a 'silver bullet'. No one would argue that there is a single solution. Although each country's government is responsible for digital health and smart city initiatives, private companies can also join the battle and help cities to defeat COVID-19 and the next pandemics. For example, inside (USA), a traffic analytics company, has updated its SafeDistance technology, which monitors a safe distance in queues and is used by realtors in buildings and offices. SafeDistance is based on iQueue inside technology, which

\footnotetext{
${ }^{14}$ https://www.smartcitiesworld.net/news/news/adelaide-invites-citizens-to-reimagine-the-city-after-thepandemic-5321

${ }_{15}^{15} \mathrm{https}$ //helsinkismart.fi/case/new-online-service-offers-open-data-on-possible-covid-19-symptoms-in-finland/

${ }^{16} \mathrm{https}: / /$ www.nyehealth.org/about/

${ }^{17} \mathrm{https} / / /$ www.smartcitiesworld.net/news/how-5g-poweredrobots-are-helping-china-fight-coronavirus-5154

${ }_{18}^{18} \mathrm{https}: / / \mathrm{www}$. straitstimes.com/singapore/iswaran-public-engagement-needs-to-be-two-way

${ }^{19} \mathrm{https}: / / \mathrm{www} . s m a r t c i t i e s w o r l d . n e t / n e w s / h o w-5$ g-poweredrobots-are-helping-china-fight-coronavirus-5154
} 
is used to monitor and analyze passenger flows at checkpoints at airports and other public places. Special sensors are placed in all rooms and collect the data needed to predict or record crowds. In this way, building managers can ensure that people keep their distance around the clock and take action in the event of violations.

In China, such companies such as Alibaba and Tencent have done a lot to ease the pandemic repercussions, managing large amounts of data. Many private companies are initiating projects and allocating funds to fight the COVID-19 pandemic.

Finally, digital health initiatives are pivotal in smart cities to get prepared for infectious disease outbreaks. Indeed, such cities as Singapore, Seoul and many cities in China and Japan that have previously implemented digital health solutions are doing better fighting COVID-19. The cities listed in Table 2 are making use of their digital health solutions to cease the outbreak and give their citizens access to good information about the disease. However, the negative impacts of the COVID-19 pandemic should push additional pressure on them, demanding new technologies and solutions in the near future.

Smart city tools are going to be key to easing lockdown restrictions. According to a study by consulting firm ABI Research (USA), the coronavirus pandemic has forced cities around the world to use technology more actively. The study also found that in the vast majority of cities, the authorities resorted to measures that required a high level of improvisation, but most successfully met the challenges of those that used technologies related to management and service delivery ${ }^{20}$.

The list of the most common technologies used by cities around the world during a pandemic is as follows: drones: to communicate and follow the rules of social distance, and to deliver medical supplies, new types of observation (remote measurement of body temperature based on artificial intelligence), autonomous transportation, dashboards and real-time data exchange (in particular, the use of data from smartphones to track location).

\section{Conclusion}

The COVID-19 pandemic which was declared on 11 March 2020 by the WHO has affected countries in the whole world and dramatically changed the lives of millions. We still do not know the final death toll and its negative economic impacts, but facing the repercussions from this pandemic, we are completely convinced that the mankind must be prepared for further outbreaks in the best possible way. As researchers have linked long-term

\footnotetext{
${ }^{20}$ https://www.abiresearch.com/press/covid-19-pandemic-impact-global-rd-spend-ai-healthcare-andpharmaceuticals
} 
exposure to polluted air to higher coronavirus mortality, municipalities are seeking to reduce traffic on streets around the world.

The COVID-19 outbreak has made a significant difference to our way of life. And because scientists estimate that by $2050,68 \%$ of the world's population will live in megacities, there is a growing need to design pandemic-resistant cities.

Smart cities, especially during the epidemic, need to be localized and made selfsufficient in terms of food and medicine supplies, medical and administrative services. City districts should be planned so that everything necessary for life is available within a 20minute walk. Such initiatives not only improve the well-being, but are also important for the mental well-being of citizens. In addition, all key infrastructure elements of smart cities must be connected by an electronic data accounting system.

It has been discussed in this study that data plays a crucial role in predicting, detecting, and mitigating a pandemic. Cities authorities can retrieve data from different sources and it is their responsibility to digitize their services in order to increase data sources as they adopt laws and allocate budgets. Citizens and private companies should be actively involved in this process. The best solution to relieve any emergency is to be prepared in advance, so the world should start to prepare for the next pandemic.

It is practically impossible to suggest a golden rule which can work in any situation even though a lot of works have been surveyed. Generally speaking, it is necessary to consider each case in particular while implementing the most appropriate technologies and systems. The studied cities provide some tips and hints what can work well, but challenges faced by each urban area must be faced and addressed separately. It is obvious that the more efficient smart city is the quicker it can respond outbreaks, which may be crucial when saving peoples' lives.

\section{References:}

1. ABI Research. Taking Stock of COVID-19 The Short- and Long-Term Ramifications on Technology and End Markets Available at: https://www.abiresearch.com/press/covid-19-pandemic-impact-global-rd-spend-ai-healthcareand-pharmaceuticals [Accessed: 2 December 2020].

2. Adelaide invites citizens to reimagine the city after the pandemic (2020), SmartCitiesWorld news 1 June [online]. Available at: https://www.smartcitiesworld.net/ news/news/adelaide-invites-citizens-to-reimagine-the-city-after-the-pandemic-5321

[Accessed: 5 September 2020]. 
3. Allam, Z., Jones, D.S. (2020), 'On the coronavirus (COVID-19) outbreak and the smart city network: universal data sharing standards coupled with artificial intelligence (AI) to benefit urban health monitoring and management', Healthcare, 8, (1), p. 46. https://doi.org/10.3390/healthcare8010046

4. Ali, S.H., Keil, R. (2006), 'Global cities and the spread of infectious disease: the case of severe acute respiratory syndrome (SARS) in Toronto, Canada', Urban Studies, 43, (3), pp. 491-509. https://doi.org/10.1080/00420980500452458

5. Astarita, V., Giofrè, V.P., Guido, G., et al. (2020), Mobile computing for disaster emergency management: empirical requirements analysis for a cooperative crowdsourced system for emergency management operation. Smart Cities, 3, (1), pp. 31-47. https://doi.org/10.3390/smartcities3010003

6. Baharudin H. (2020), 'Iswaran: Public engagement needs to be two-way', The Straits Time, 5 December Available at: https://www.straitstimes.com/singapore/iswaranpublic-engagement-needs-to-be-two-way [Accessed: 5 December 2020].

7. Budd, L., Bell, M., Brown, T. (2009), Of plagues, planes and politics: controlling the global spread of infectious diseases by air. Political Geography, 28, (7), pp.426-435. https://doi.org/10.1016/j.polgeo.2009.10.006

8. Bernard, E., Titov, V. (2015), Evolution of tsunami warning systems and products. Philosophical Transactions of the Royal Society A, Mathematical, Physical and Engineering Sciences, 373, (2053), https://doi.org/10.1098/rsta.2014.0371

9. Chamoso, P., González Briones, A., Prieta, F.D.L., et al. (2020), Smart city as a distributed platform: toward a system for citizen-oriented management. Computer Communications, 152, pp. 323-332. https://doi.org/10.1016/j.comcom.2020.01.059

10. Costa, D.G., de Oliveira, F.P. (2020), A prioritization approach for optimization of multiple concurrent sensing applications in smart cities. Future Generations Computer Systems, 108, pp. 228-243. https://doi.org/10.1016/j.future.2020.02.067

11. Costa, D.G., Vasques, F., Portugal, P., et al. (2019), A distributed multi-tier emergency alerting system exploiting sensors-based event detection to support smart city applications. Sensors, 20, (1), pp. 1-28. https://doi.org/10.3390/s20010170

12. Covid vaccine update: When will others be ready? Available at: https://www.bbc.com/news/health-51665497 [Accessed: 6 December, 2020].

13. Joss, S., Sengers, F., Schraven, D., Caprotti F. \& Dayot, Y. (2019), The Smart City as Global Discourse: Storylines and Critical Junctures across 27 Cities, Journal of Urban Technology, 26 (1) https://doi.org/10.1080/10630732.2018.1558387 
14. Kummitha, R.K.R. (2020), Smart technologies for fighting pandemics: the techno and human-driven approaches in controlling the virus transmission, Government Information Quarterly. https://doi.org/10.1016/j.giq.2020.101481

15. Lu, H.P., Chen, C.S., Yu, H. (2019), Technology roadmap for building a smart city: an exploring study on methodology. Future Generations Computer Systems, 97, pp. 727-742. https://doi.org/10.1016/j.future.2019.03.014

16. Mohammadi, M., Al-Fuqaha, A., Guizani, M., et al. (2018), Semisupervised deep reinforcement learning in support of IoT and smart city services. IEEE Internet of Things Journal, 5, (2), pp. 624-635, https://doi.org/10.1109/JIOT.2017.2712560

17. Moreno, M.V., Terroso-Saenz, F., Gonzalez-Vidal, A., et al. (2017), Applicability of big data techniques to smart cities deployments. IEEE Transactions on Industrial Informatics, 13, (2), pp. 800-809. https://doi.org/10.1109/TII.2016.2605581

18. New online service offers open data on possible Covid-19 symptoms in Finland. Available at: https://helsinkismart.fi/case/new-online-service-offers-open-data-on-possiblecovid-19-symptoms-in-finland/ [Accessed: 5 August 2020].

19. Nikolay, B., Salje, H., Sturm Ramirez, K., et al. (2017), Evaluating hospital-based surveillance for outbreak detection in Bangladesh: analysis of healthcare utilization data. PLOS Medicine 14, (1), pp. 1-18. https://doi.org/10.1371/journal.pmed.1002218

20. NYeC. About NYeC, (2020). Available at https://www.nyehealth.org/about/ [Accessed: 5 August 2020].

21. Payments Source. Morning brief 3.4.20: Alipay's coronavirus 'health code' feeds payment data to police (2020). Available at https://www.paymentssource.com/news/alipayscoronavirus-health-codefeedspayment-data-to-police [Accessed: 2 December 2020].

22. Peng, W., Gao, W., Liu, J. (2019), AI-Enabled massive devices multiple access for smart city. IEEE Internet Things Journal, 6, (5), pp. 7623-7634. https://doi.org/10.1109/JIOT.2019.2902448

23. Pirouz, B., Shaffiee Haghshenas, S., Shaffiee Haghshenas, S., et al. (2020), Investigating a serious challenge in the sustainable development process: analysis of confirmed cases of COVID-19 (new type of coronavirus) through a binary classification using artificial intelligence and regression analysis. Sustainability, 12, (6), pp. 1-21. https://doi.org/10.3390/su12062427

24. Rabi, F.A., Al Zoubi, M.S., Kasasbeh, G.A., et al. (2020), SARS-Cov-2 and coronavirus disease 2019: what we know so far. Pathogens, 9, (3), pp. 1-14. https://doi.org/10.3390/pathogens9030231 
25. Rehman, S.U., Shafique, L., Ihsan, A., et al. (2020), 'Evolutionary trajectory for the emergence of novel coronavirus SARS-Cov-2', Pathogens, 9, (3), p. 240. https://doi.org/10.3390/pathogens 9030240

26. Region, H.S. Health \& wellness smart cases, (2020), Available at https:// helsinkismart.fi/human-health-tech/ [Accessed: 1 September 2020].

27. Samuel, C., Siebeneck, L.K. (2019), Roles revealed: an examination of the adopted roles of emergency managers in hazard mitigation planning and strategy implementation. International Journal of Disaster Risk Reduction, 39, p. 101-145. https://doi.org/10.1016/j.ijdrr.2019.101145

28. Senate department for urban development and the environment - smart city strategy Berlin, 2015. Available at https://www.berlin-partner.de/ [Accessed: 1 September 2020].

29. Shah, S.A., Seker, D.Z., Rathore, M.M., et al. (2019), Towards disaster resilient smart cities: an internet of things and big data analytics be the game changers? IEEE Access, 7 , pp. 91885-91903. https://doi.org/10.1109/ACCESS.2019.2928233

30. Short, K.R., Richard, M., Verhagen, J.H., et al. (2015), One health, multiple challenges: the inter-species transmission of influenza a virus. One Health, 1, pp. 1-13. https://doi.org/10.1016/j.onehlt.2015.03.001

31. Silva, B.N., Khan, M., Han, K. (2018), Towards sustainable smart cities: a review of trends, architectures, components, and open challenges in smart cities. Sustain. Cities Soc., 38, pp. 697-713. https://doi.org/10.1016/j.scs.2018.01.053

32. SmartCitiesWorld (2020) 'South Korea to step-up online coronavirus tracking', 2020. Available at https://www.smartcitiesworld.net/news/news/south-koreato-stepup-onlinecoronavirus-tracking-5109 [Accessed: 1 December 2020].

33. Smart Cities World. How 5g-powered robots are helping China fight coronavirus. Available at https://www.smartcitiesworld.net/news/how-5g-poweredrobots-are-helpingchina-fight-coronavirus-5154 [Accessed: 1 December 2020].

34. Soyata, T., Habibzadeh, H., Ekenna, C., et al. (2019), Smart city in crisis: technology and policy concerns. Sustainable Cities and Society, 50, 101566. https://doi.org/10.1016/j.scs.2019.101566

35. Trencher, G., Karvonen, A. (2019), 'Stretching 'smart': advancing health and wellbeing through the smart city agenda', Local. Environ., 24, (7), pp. 610-627. https://doi.org/10.1080/13549839.2017.1360264 
36. United Nations (2020). 'UN Launches COVID-19 Plan that Could Defeat the Virus and Build a Better World,' UN News, 31 March. Available at https://news.un.org/en/story/2020/03/1060702 [Accessed: 5 December 2020].

37. Vellingiri, B., Jayaramayya, K., Iyer, M., et al. COVID-19: a promising cure for the global panic (2020), Science of the Total Environment, 725, p. 138277. https://doi.org/10.1016/j.scitotenv.2020.138277

38. Veovo Introduces Airport Social Distancing Solutions for Safer Travel Available at https://veovo.com/discover/news/airport-social-distancing-solution/ [Accessed: 5 December 2020].

39. Webb, W., Toh, C. (2020), The smart city and COVID-19. IET Smart cities, $2020 .$. https://doi.org/10.1049/iet-smc.2020.0024

40. Xu, B., Li, L., Hu, D., et al. (2018), Healthcare data analysis system for regional medical union in smart city. Journal of Management Analytics, 5, (4), pp. 334-349. https://doi.org/10.1080/23270012.2018.1490211 